\title{
A New Family of Rigid Dienone Musks Challenges the Perceptive Range of the Human Olfactory Receptor OR5AN1
}

\author{
Jie Liu ${ }^{\mathrm{a}, \mathrm{d}}(0)$ \\ Vera Hürlimann ${ }^{b}($ (1) \\ Roger Emter ${ }^{b}$ \\ Andreas Natsch ${ }^{b} \odot$ \\ Carmen Esposito $\sqrt{ }(0)$ \\ Stephanie M. Linker ${ }^{c}(\mathbb{0}$ \\ Yue Zoud $($ () \\ Lijun Zhoud ${ }^{d}(\mathbb{0}$ \\ Quanrui Wang*a (1) \\ Sereina Riniker*c(i) \\ Philip Kraft ${ }^{* b}$ ( \\ a Department of Chemistry, Fudan University, 2205 Songhu \\ Road, Shanghai, 200438, P. R. of China \\ qrwang@fudan.edu.cn \\ b Givaudan Fragrances S\&T, Ingredients Research, \\ Kemptpark 50, 8310 Kemptthal, Switzerland \\ philip.kraft@givaudan.com \\ c Department of Chemistry and Applied Biosciences, ETH \\ Zürich, Vladimir-Prelog-Weg 2, 8093 Zürich, Switzerland \\ sriniker@ethz.ch \\ dGivaudan Fragrances (Shanghai) Ltd, 298 Li Shi Zhen Road, \\ Shanghai, 201203, P. R. of China \\ Dedicated to the memory of Professor Georg Fráter \\ ( 27 September 1941; $† 25$ June 2019)
}

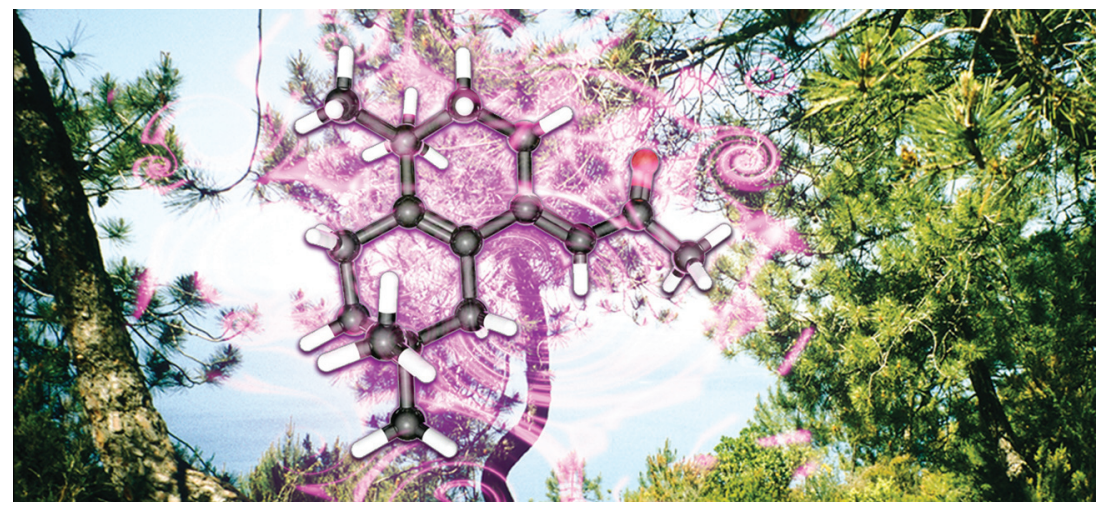

Received: 13.02.2020

Accepted after revision: 08.03.2020

Published online: 24.03 .2020

DOI: 10.1055/s-0040-1708009; Art ID: st-2020-b0088-I

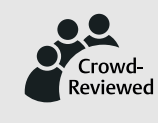

Abstract A new family of dienone musks was discovered by alkylation of different aldehydes with but-3-en-1-yn-1-yllithium and subsequent domino reaction of a Saucy-Marbet transfer vinylation-Claisen rearrangement with an intramolecular Diels-Alder reaction, and concluding Lewis acid catalyzed double-bond isomerization. The newly synthesized dienone structures possess pleasant musk odors displaying fatty, slightly fruity and green facets. Although the dienone musks were predicted in silico to bind to the OR5AN1 receptor based on QM/MM calculations, they were found to be inactive in the in vitro assay. The latter results suggest that the OR5AN1 receptor is not the prime musk receptor but primarily responsible for the animalic character of certain macrocyclic ketones and nitro musks.

Key words fragrances, musk odorants, odorant receptors, olfactory properties, structure-activity relationships

A window open onto an Italian cliff.

Liguria, cluster pines, summertime. [...]

It is like some imaginary musk,

a fairy tale, something more real than reality.

Daniela Andrier, Joy - The Brightness of Life ${ }^{1}$
Like no other perfumery material, musks embody seductive sensuality, irresistible attraction and erogenous magnetism, attributes that define a perfume: Musks make us dream. ${ }^{1}$ Abstracted from the complex odor of Tonquin musk (Moschus moschiferus L.) tincture with its principle odorant $(R)-(-)$-muscone (1, Figure 1$)$, musks come in many different molecular shapes and fragrant tonalities. ${ }^{2}$ However, in terms of odor, there are two main subfamilies: the animalic-powdery type with the nitro arene musk ketone (2) and $(R)-(-)$-muscone $(\mathbf{1})$ being most representative, and the musky-floral type with the macrolide Thibetolide/Exaltolide (3) as well as the polycyclic aromatic musk (PCM) Galaxolide (4) as major representatives. The more recent fourth class of linear alicyclic musks, with Sylkolide $(\mathbf{5})^{3}$ as example, also belongs to the musky-floral family. In principle, this is also true for the latest class of musk odorants that derived from $\mathbf{6}$ as principal lead structure discovered during derivatization of carotol. ${ }^{4}$ This fifth class features a dienone motif with the terminal $(E)$-double bonds substituted by two bulky moieties, as exemplified in compounds 7-10., 5 The steric bulk on the $\gamma$-carbon atom is most important for the muskiness, as demonstrated in $7,{ }^{5}$ but the sila-derivative $\mathbf{1 1}$ in comparison with $\mathbf{7}$ indicated that the size of the TMS group already slightly exceeds the optimal dimensions of the binding pocket, as indicated by the in- 
creased odor perception threshold (th). ${ }^{7}$ The $\gamma, \delta$-double bond outweighs the contribution of the $\alpha, \beta$-double bond, ${ }^{8}$ but both are indispensable for a musk odor sensation. Whereas linear alicyclic musks display fruity side notes in the direction of raspberry as in the case of Sylkolide (5) or pear for Helvetolide, the dienone musks tend towards green aspects as in $\mathbf{1 0}$ and $\mathbf{1 1}$ or earthy facets as manifest in the beetroot character of $\mathbf{9}$.

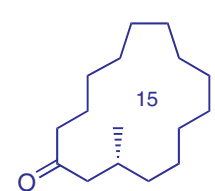

1

$$
\begin{gathered}
1 \\
\text { (R)-(-)-muscone } \\
\text { musky, animalic, } \\
\text { powdery }
\end{gathered}
$$
$0.59 \mathrm{ng} / \mathrm{L}$ air

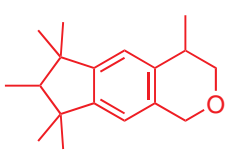

4

Galaxolide

musky, floral th $0.9 \mathrm{ng} / \mathrm{L}$ air<smiles>CC(=O)/C=C/C(=CC(C)C)C(C)(C)C</smiles>

7

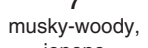

ionone

th $0.66 \mathrm{ng} / \mathrm{L}$ air

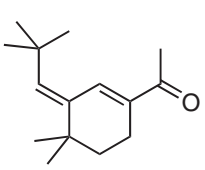

10

musky, green-

floral, muguet th $0.90 \mathrm{ng} / \mathrm{L}$ air

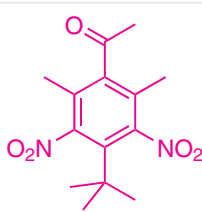

$$
\begin{gathered}
2 \\
\text { musk ketone } \\
\text { musky, animalic, } \\
\text { powdery } \\
0.1 \mathrm{ng} / \mathrm{L} \text { air }
\end{gathered}
$$
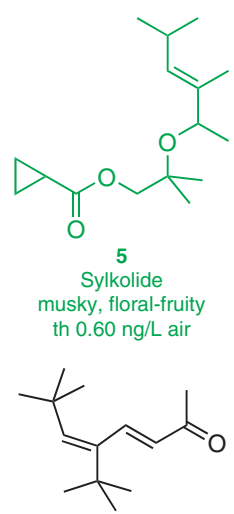

8
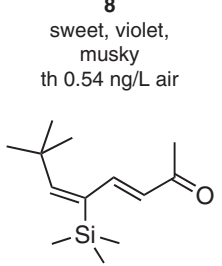

11

floral-fatty musk

rose, sl. green

th $10.6 \mathrm{ng} / \mathrm{L}$ ai

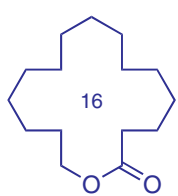

3

Thibetolide/

Exaltolide

musky, floral

$1.4 \mathrm{ng} / \mathrm{L}$ air
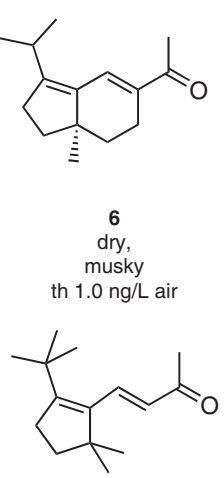

9

musky, beetroot,

dried fruits

th $0.26 \mathrm{ng} / \mathrm{L}$ air

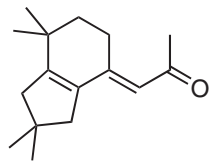

12

musky, sl. fatty,

sl. green

th $2.9 \mathrm{ng} / \mathrm{L}$ ai
Figure 1 The five different classes of musk odorants: Macrocyclic ketones $\mathbf{1}$, nitro musks $\mathbf{2}$, macrocyclic lactones $\mathbf{3}$, polycyclic musks (PCM) $\mathbf{4}$, linear alicyclic musks $\mathbf{5}$, and the most recently discovered dienone musks 6-12

Since tandem sigmatropic rearrangements of vinyl propargyl systems with allenylic intramolecular DielsAlder (IMDA) reactions offer facile access to tetrahydroindenes, ${ }^{9}$ we had the idea to construct novel conformationally confined bicyclic dienone musks by developing a new domino reaction that combines a propargyl Claisen rearrangement ${ }^{10}$ with an allenylic IMDA. As outlined in Scheme 1, 2,2,5-trimethyl-4-hexenal (13), easily available for instance by enolate alkylation of isobutyraldehyde with prenyl ha- lides, ${ }^{11}$ was reacted with but-3-en-1-yn-1-yl lithium to provide the dienyne alcohol 15 in $96 \%$ yield. In the presence of trace amounts of $p$-toluenesulfonic acid monohydrate, Saucy-Marbet reaction ${ }^{12}$ of $\mathbf{1 5}$ with isopropenyl methyl ether (16) then furnished in an efficient domino reaction consisting of [3,3]-sigmatropic rearrangement of $\mathbf{1 7}$ and subsequent IMDA of the allenylic intermediate 18, the 2,6,7,7a-tetrahydro- $1 H$-inden-4-yl ketone $\mathbf{1 9}$ in $85 \%$ yield. This unconjugated dienone $\mathbf{1 9}$ was devoid of any musk character and possessed a woody-green odor with carrotlike earthy aspects instead. We were however much delighted to find the sought-after musk note upon isomerization of the dienone system of $\mathbf{1 9}$ with aluminum trichloride, which afforded in 51\% yield the new conjugated dienone musk 12 with tetrasubstituted $\gamma, \delta$-double bond and an encouraging threshold of $2.9 \mathrm{ng} / \mathrm{L}$ air.

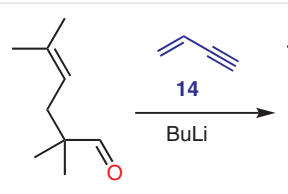

13

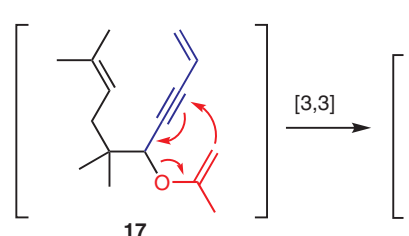

17

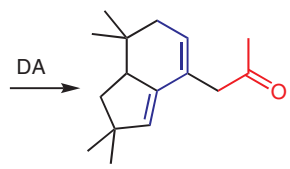

19

woody, green, carrot th $500 \mathrm{ng} / \mathrm{L}$ air

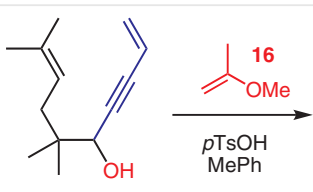

15

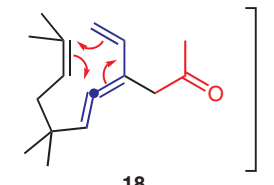

18

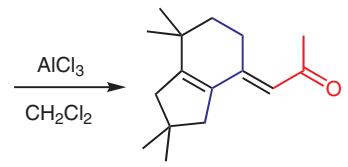
musky, sl. fatty, sl. gree th $2.9 \mathrm{ng} / \mathrm{L}$ air
Scheme 1 Synthetic route to the bicyclic dienone musk 12

Although slightly weaker than the representatives 6-10, this new musk 12 is with $\mathrm{C}_{16} \mathrm{H}_{24} \mathrm{O}$ (232.37 $\mathrm{u}$ ) both heavier and more rigid in structure than these leads. Since the sequence delineated in Scheme 1 allowed for easy variation of the substitution patterns, we investigated the structureodor correlation of this new family with the derivatives summarized in Figure 2.

While the gem-dimethyl cyclopentyl substituent of $\mathbf{9}$ is at a different position in 12, it is essential nonetheless: The nor structure $\mathbf{2 0}$ is greener and weaker (th $21 \mathrm{ng} / \mathrm{L}$ air) but still musky, and so is the ethyl derivative 21 (th $40 \mathrm{ng} / \mathrm{L}$ air), though it is less green. Interestingly, the isopropyl derivative 22 (th $25 \mathrm{ng} / \mathrm{L}$ air) is somewhat stronger again than the ethyl derivative 21, and this goes together with a pronounced green tonality. In contrast, the spiro[cyclohexane1,2'-inden] system 23 definitely exceeds the boundaries of the musk receptor and thus, $\mathbf{2 3}$ is devoid of any musk char- 


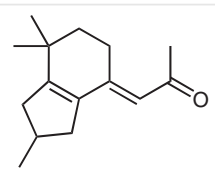

20
green, musky,
fatty, sl. fruity, fatty, sl. fruity,
th $21 \mathrm{ng} / \mathrm{L}$ air

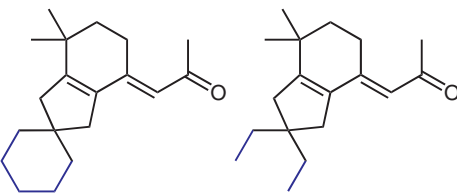

23

weak, woody,

fruity-floral

th $310 \mathrm{ng} / \mathrm{L}$ air

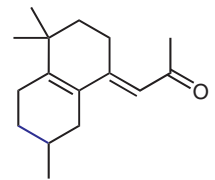

26
green, fatty,
musky
th $30 \mathrm{ng} / \mathrm{L}$ air

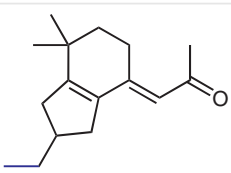

21

musky, fatty, weak th $40 \mathrm{ng} / \mathrm{L}$ air

24 odorless

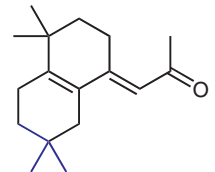

27 musky, fatty,
sl. fruity, green sl. fruity, green
th $0.4 \mathrm{ng} / \mathrm{L}$ air

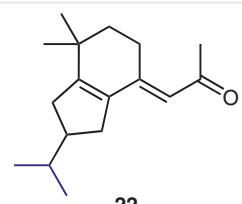
green, musky, powdery, fruity, th $25 \mathrm{ng} / \mathrm{L}$ air

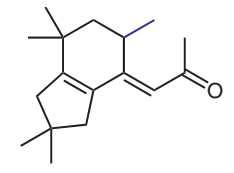

25

green, aromatic, fruity, clary sage th $94 \mathrm{ng} / \mathrm{L}$ air

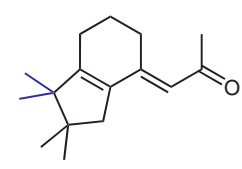

28
odorless
Figure 2 Olfactory properties of the new dienone musks 20-28

acter. Its gem-diethyl seco-structure $\mathbf{2 4}$ is completely odorless even. Similarly, the additional methyl substituent on the cyclohexyl ring in $\mathbf{2 5}$ eradicated the muskiness of $\mathbf{1 2}$, and the compound smelled green, aromatic, and fruity in the direction of clary sage. Incorporating one cyclopentenyl methyl group as methylene unit into the ring enlarges the system to the $3,4,5,6,7,8$-hexahydronaphthalen- $1(2 \mathrm{H})$ ylidene 26, which is musky-green and comparable with 20-22 in terms of intensity. Adding another methyl group at $\mathrm{C}^{-} \mathbf{7}^{\prime}$, however, culminated in the most intense dienone musk 27 of this new series, possessing a pleasant musk odor with fatty, slightly fruity and again green facets. With an odor threshold of $0.4 \mathrm{ng} / \mathrm{L}$ air it is almost as intense as the most potent dienone musk $\mathbf{9}(0.26 \mathrm{ng} / \mathrm{L}$ air $)$ reported so far. Compound $\mathbf{2 8}$ finally demonstrates that the bulky substructures on the $\gamma$ - and $\delta$ - carbon atom of the dienone backbone should be trans-configured, since it is, with its two adjacent gem-dimethyl groups in the $\gamma, \delta$-annulating cyclopentenyl ring, completely odorless.

Since this new family of dienone musks 12 (2.9 ng/L air) and $\mathbf{2 0 - 2 7}$ is structurally rather rigid and conformationally confined, it should be ideally suited to characterize the spectrum of activity of the OR5AN1 receptor, which was considered to be the prime human musk receptor. ${ }^{13}$ Ahmed et al. ${ }^{14}$ had reported a positive correlation between EC50 values and calculated $\mathrm{QM} / \mathrm{MM}$ binding energies of a series of musk odorants to OR5AN1. These binding energies were obtained from docking into a homology model of OR5AN1 followed by QM/MM optimization. We first reconstructed the published protocol with open-source tools, and validated it using the homology model and ten compounds from the original reference ${ }^{14}$ (for details see the Supporting Information). Our results reproduced the correlation between the QM/MM binding energies and the experimental EC50 values as observed previously ${ }^{14}$ (cf. the Supporting Information). Subsequently, we calculated the QM/MM binding energy of novel compounds $\mathbf{9}, \mathbf{1 2}, \mathbf{2 0 - 2 3}, \mathbf{2 6 - 2 7}$ by using the same protocol (Table 1). For all compounds, the important hydrogen bond with Tyr260 and the hydrophobic interactions with the surrounding Phe residues as described previously ${ }^{14}$ were established, and the resulting $\mathrm{QM} / \mathrm{MM}$ binding energies were found to be in a similar range as reported for the known musk odorants. ${ }^{14}$ As an example, the top poses of the lead compound $\mathbf{9}$ and the new musk 12 are shown in Figure 3. Interestingly, although the two odorants display the same key interactions, the dienone moieties do not superimpose. This observation can be explained by the relatively large binding pocket, which allows for different binding modes to form a hydrogen bond with Tyr260 with only small differences in binding energy.

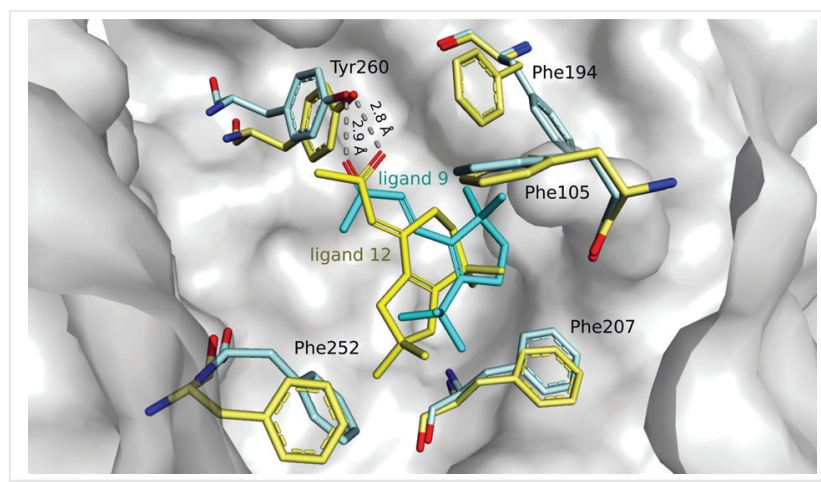

Figure 3 Top binding poses (QM/MM geometry optimized) of compounds 9 (cyan) and 12 (yellow) with the homology model of OR5AN1. Key residues in the binding pocket (Tyr260, Phe105, Phe194, Phe207, Phe252) are shown in color. In addition, the hydrogen bond between the carbonyl group of the ligands and Tyr260 is indicated.

Based on the calculations, all dienone musks $\mathbf{9}, \mathbf{1 2}, \mathbf{2 0}$ 23 and 26-27 were predicted to bind to the OR5AN1 musk receptor with $\mathrm{QM} / \mathrm{MM}$ binding energies $E_{\text {bind }}$ comparable to those of the reference musks reported previously. ${ }^{14}$ To test this prediction, the OR5AN1 receptor was expressed in HEK293 cells along with RTP1S and a luciferase reporter gene according to ref. ${ }^{14}$ While the results from the literature were confirmed, including the weak activation by Thibetolide/Exaltolide (3), no activation of OR5AN1 by the dienone musks 9, 12, 20-23, 26-27 (Table 1) was observed (only compounds $>10 \%$ relative efficacy were considered activators). Since, however, the dienones do smell musky, other receptors must be involved. Recently, the OR5A2 receptor was reported to be activated by a diverse range of musk odorants, ${ }^{15}$ indicating that OR5A2 might be the prime musk receptor. However, when we transfected OR5A2 along with 
Table 1 Comparison of Calculated QM/MM Binding Energy $E_{\text {bind }}[\mathrm{kcal} / \mathrm{mol}]$ Profiles, Measured $\mathrm{EC}_{50}[\mu \mathrm{M}]$, and Relative Efficacy [\%] for the Human OR5AN1 Musk Receptor

\begin{tabular}{|c|c|c|c|}
\hline Compound & $\begin{array}{l}E_{\text {bind }}[\mathrm{kcal} / \mathrm{mol}] \\
\text { (OR5AN1) }\end{array}$ & $\begin{array}{l}\mathrm{EC}_{50} \\
\text { (OR5AN1) }^{\mathrm{a}}\end{array}$ & $\begin{array}{l}\text { Relative efficacy [\%] } \\
\text { (OR5AN1) }^{\mathrm{b}}\end{array}$ \\
\hline 3 (Thibetolide/Exaltolide) & -53.1 & 7.4 & 16 \\
\hline 4 (Galaxolide) & -45.5 & n.i. & 6 \\
\hline Cyclohexadecanone & -45.4 & 9.4 & 52 \\
\hline Cyclohexadec-5-en-1-one (Velvione) & -45.9 & 6.4 & 48 \\
\hline 1-(tert-Butyl)-3,5-dimethyl-2,4,6-trinitrobenzene (musk xylene) & -48.1 & 1.0 & 73 \\
\hline 1-(tert-Butyl)-3,4,5-trimethyl-2,6-dinitrobenzene (musk tibetene) & -55.9 & 0.88 & 100 \\
\hline Dienone musk 9 & -45.3 & n.i. & 8 \\
\hline Dienone musk 12 & -49.0 & n.i. & 7 \\
\hline Dienone musk 20 & -41.8 & n.i. & 6 \\
\hline Dienone musk 21 & -41.7 & n.i. & 7 \\
\hline Dienone musk 22 & -45.7 & n.i. & 7 \\
\hline Dienone musk 23 & -53.4 & n.i. & 6 \\
\hline Dienone musk 26 & -50.9 & n.i. & 7 \\
\hline Dienone musk 27 & -48.5 & n.i. & 7 \\
\hline
\end{tabular}

n.i. = no induction.

${ }^{b}$ Relative activation to musk tibetene (=100\%).

RTP1S and RTP2 into HEK293 cells, no activation of OR5A2 by ambrettolide, musk ketone, or muscone was observed, suggesting that OR5A2 is not functionally expressed in our cell system.

The QM/MM binding energies predicted that the dienone musks 9, 12, 20-23, 26-27 bind to OR5AN1 whereas the in vitro experiments showed no activation of this receptor with these compounds (Table 1). To elucidate the reasons behind this discrepancy, we calculated the binding energy of five additional odorants, which were reported previously to not activate OR5AN1. ${ }^{14}$ For all these inactive compounds, including Galaxolide (4; Table 1), the calculated energy values were again in a similar range to those of the active compounds; i.e., they would be predicted to be active (cf. Supporting Information). These results taken together indicate that the published computational workflow, ${ }^{14}$ which was validated only against active compounds, is not able to discriminate between odorants that activate OR5AN1 and those that do not. A discussion on the possible causes of this result and on the limitations of the computational workflow is included in the Supporting Information. Briefly, we conclude that to distinguish between active and inactive compounds, it may be necessary to include entropic effects in the computational workflow, for example by characterizing the dynamics of the system both in the presence and in the absence of the odorants. This hypothesis is supported by molecular dynamics simulations of the OR5AN1-ligand complexes reported previously, ${ }^{14}$ in which substantial conformational fluctuations of the binding site were observed.
In summary, we have discovered a new family of dienone musks ${ }^{16-18}$ that does not activate the OR5AN1 receptor in vitro, although computational models predicted it would. Since only animalic-powdery musks such as ketones $\mathbf{1}$ and $\mathbf{2}$ activate OR5AN1 with significant efficacy, we believe this odorant receptor to be responsible for the animalic rather than the musk character. The prime musk receptor is then yet to be discovered and characterized, but the newly synthesized rigid dienone musks will help to shed light on which receptor that is.

\section{Funding Information}

The financial support from the National Natural Science Foundation of China (NNSFC; Grant 21971042) is as well acknowledged with gratitude.

\section{Acknowledgment}

We thank Victor Batista and co-workers for providing the homology model of OR5AN1, exemplary input files for Gaussian09 and helpful discussions on the computational workflow. We are also grateful to Cornelia Wartmann for NMR experiments, to Yumiko Weiner-Sekiya for HRMS measurements, to Sandro Dossenbach, his team and their panelists for the determination of odor thresholds, and to Dominique Lelievre for the olfactory evaluation. For the background picture of the Ligurian coastal forest with its unique musky sun-struck resin scent that we used in the graphical abstract, we are indebted to Roman Kaiser. 


\section{Supporting Information}

Supporting information for this article is available online at https://doi.org/10.1055/s-0040-1708009.

\section{References and Notes}

(1) Andrier, D. In Joy: The Brightness of Life, In Bulgari: The Perfume of Gems; Marchettti, S., Ed.; Rizzoli: New York, 2018.

(2) Kraft, P. In Chemistry and Technology of Flavors and Fragrances; Rowe, D. J., Ed.; Blackwell Publishing: Oxford, 2005, 143.

(3) Kraft, P.; Eichenberger, W. Eur. J. Org. Chem. 2004, 354.

(4) Kula, J.; Bonikowski, R.; Staniszewska, M.; Krakowiak, A.; Wieczorek, M. W.; Majzner, W. R.; Bujacz, G. D. Eur.J. Org. Chem. 2002, 1826.

(5) Kraft, P.; Popaj, K. Tetrahedron 2006, 62, 12211.

(6) Kraft, P.; Popaj, K. Eur. J. Org. Chem. 2008, 4806.

(7) Geyer, M.; Bauer, J.; Burschka, C.; Kraft, P.; Tacke, R. Eur. J. Inorg. Chem. 2011, 2769.

(8) Kraft, P.; Jordi, S.; Denizot, N.; Felker, I. Eur. J. Org. Chem. 2014, 554.

(9) For selected examples, see: (a) Gibbs, R. A.; Bartels, K.; Lee, R. W. K.; Okamura, W. H. J. Am. Chem. Soc. 1989, 111, 3717. (b) Curtin, M. L.; Okamura, W. H. J. Org. Chem. 1990, 55, 5278. (c) Gidlöf, R.; Johansson, M.; Sterner, O. Org. Lett. 2010, 12, 5100. (d) Zhao, Y.; Jin, J.; Boyle, J. W.; Lee, B. R.; Day, D. P.; Susanti, D.; Clarkson, G. J.; Chan, P. W. H. J. Org. Chem. 2017, 82, 2826.

(10) For a general review on propargyl Claisen rearrangements see: Tejedor, D.; Méndez-Abt, G.; Cotos, L.; García-Tellado, F. Chem. Soc. Rev. 2013, 42, 458.

(11) Mayr, H.; Heilmann, W.; Bäuml, E.; Vorbrüggen, H. Chem. Ber. 1991, 124, 203.

(12) Saucy, G.; Marbet, R. Helv. Chim. Acta 1967, 50, 1158.

(13) Sato-Akuhara, N.; Horio, N.; Kato-Namba, A.; Yoshikawa, K.; Niimura, Y.; Ihara, S.; Shirasu, M.; Touhara, K. J. Neurosci. 2016, $36,4482$.

(14) Ahmed, L.; Zhang, Y.; Block, E.; Buehl, M.; Corr, M. J.; Cormanich, R. A.; Gundala, S.; Matsunami, H.; O'Hagan, D.; Ozbil, M.; Pan, Y.; Sekharan, S.; Ten, N.; Wang, M.; Yang, M.; Zhang, Q.; Zhang, R.; Batista, V. S.; Zhuang, H. Proc. Natl. Acad. Sci. 2018, 115, E3950.

(15) Huysseune, S.; Veithen, A.; Quesnel, Y. (ChemCom S.A.) PCT Int. Pat. Appl WO 2019/110630 A1, prior. December 5, 2017; Chem. Abstr. 2019, 171, 69645

(16) Saucy-Marbet/IMDA Reaction to Ketone 19: A 100-mL autoclave was charged with a mixture of vinyl propargyl alcohol $\mathbf{1 5}$ $(2.69 \mathrm{~g}, 14.0 \mathrm{mmol})$, isopropenyl methyl ether (16, 4 equiv, 4.04 g, $56.0 \mathrm{mmol}), p$-toluenesulfonic acid monohydrate $(2 \mathrm{mg})$ and toluene $(40 \mathrm{~mL})$. The reaction mixture was heated to $150^{\circ} \mathrm{C}$ for $24 \mathrm{~h}$, prior to removal of the solvent and purification by flash chromatography (PE/MTBE $=95: 5, R_{f} 0.44$ ) and bulb-to-bulb distillation, which furnished the tetrahydroindenyl ketone $\mathbf{1 9}$ (2.8 g, $85 \%$, b.p. $152^{\circ} \mathrm{C} / 0.18 \mathrm{mbar}$ ) as a colorless odoriferous liquid.

(17) Isomerization of 19 to the Dienone Musk 12: At $0{ }^{\circ} \mathrm{C}, \mathrm{AlCl}_{3}$ ( 0.1 equiv, $58 \mathrm{mg}, 0.43 \mathrm{mmol}$ ) was added to a solution of ketone $19(1.0 \mathrm{~g}, 4.3 \mathrm{mmol})$ in dichloromethane $(20 \mathrm{~mL})$. The resulting mixture was stirred for $2 \mathrm{~h}$ at this temperature, and then allowed to warm to room temp. After stirring overnight, quenching with $1 \mathrm{M}$ aq. $\mathrm{HCl}$, extraction with dichloromethane $(3 \times 30 \mathrm{~mL})$, and purification by flash chromatography (PE/MTBE $=95: 5, R_{f} 0.43$ ) with subsequent bulb-to-bulb distillation provided the $(E)$-configured dienone musk $12(510 \mathrm{mg}$, $51 \%$, b.p. $\left.140{ }^{\circ} \mathrm{C} / 0.14 \mathrm{mbar}\right)$ as pale-yellow liquid. ${ }^{1} \mathrm{H}$ NMR (400 $\left.\mathrm{MHz}, \mathrm{CDCl}_{3}\right): \delta=5.82(\mathrm{~s}, 1 \mathrm{H}, 3-\mathrm{H}), 2.98(\mathrm{td}, J=6.5,2.0 \mathrm{~Hz}, 2 \mathrm{H}$, $\left.5^{\prime}-\mathrm{H}_{2}\right), 2.30\left(\mathrm{~s}, 2 \mathrm{H}, 3^{\prime}-\mathrm{H}_{2}\right), 2.27-2.25\left(\mathrm{~m}, 2 \mathrm{H}, 1^{\prime}-\mathrm{H}_{2}\right), 2.19(\mathrm{~s}, 3 \mathrm{H}$, $\left.1-\mathrm{H}_{3}\right), 1.55\left(\mathrm{t}, J=6.5 \mathrm{~Hz}, 2 \mathrm{H}, 6^{\prime}-\mathrm{H}_{2}\right), 1.09\left(\mathrm{~s}, 6 \mathrm{H}, \mathrm{Me}_{2} \mathrm{C}-2^{\prime}\right), 1.02$ (s, $\left.6 \mathrm{H}, \mathrm{Me}_{2} \mathrm{C}-7^{\prime}\right)$ ppm. ${ }^{1} \mathrm{H},{ }^{1} \mathrm{H}$ NOESY $\left(500 \mathrm{MHz}, \mathrm{CDCl}_{3}\right): 1-\mathrm{H}_{3} \times 5^{\prime}-$ $\mathrm{H}_{2}, 3-\mathrm{H} \times 33^{\prime}-\mathrm{H}_{2} \cdot{ }^{13} \mathrm{C}$ NMR $\left(100 \mathrm{MHz}, \mathrm{CDCl}_{3}\right): \delta=199.2(\mathrm{~s}, \mathrm{C}-2)$, 159.8 (s, C-7a'), 151.7 (s, C-4'), 132.9 (s, C-3a'), 118.1 (d, C-3), $48.0\left(\mathrm{t}, \mathrm{C}-1^{\prime}\right), 46.7\left(\mathrm{t}, \mathrm{C}-3^{\prime}\right), 37.6\left(\mathrm{t}, \mathrm{C}-6^{\prime}\right), 36.9\left(\mathrm{~s}, \mathrm{C}-2^{\prime}\right), 32.7(\mathrm{~s}, \mathrm{C}-$ 7'), 32.0 (q, C-1), 29.7 (2q, $\left.\mathrm{Me}_{2} \mathrm{C}-2^{\prime}\right), 26.3$ (2q, $\left.\mathrm{Me}_{2} \mathrm{C}-7^{\prime}\right), 24.4$ (t, C-5') ppm. Odor description: musky, slightly fatty, slightly green. Odor threshold (th): $2.9 \mathrm{ng} / \mathrm{L}$ air.

(18) In vitro OR5AN1 Assay: HEK293T cells were grown in DMEM medium containing FBS (9\%). The cells were seeded in 96-well plates $(10,000$ cells/well). After $24 \mathrm{~h}$, the cells were transfected with plasmids for the expression of human OR5AN1, a human RTP1S variant (V227I), and a cAMP-responsive element luciferase reporter using Lipofectamine 2000 according to the manufacturer's instructions. For each plate pcDNA3.1(+)-Lucy-FLAGrho-OR5AN1 $(0.625 \mu \mathrm{g})$, pcDNA3.1(+)-RTP1S-V227I $(1 \mu \mathrm{g})$ and pGL4.29 $(1 \mu \mathrm{g})$ were transfected. The cells were stimulated with the musks (dissolved in growth medium) $18 \mathrm{~h}$ post transfection. After $4 \mathrm{~h}$, the cells were lysed, and the luciferase activity was measured. Efficacy was determined as maximal activation over the full dose-response curve. $\mathrm{EC}_{50}$ values (conc. for $50 \%$ efficacy) were determined by the Graph pad prism program v 6.09 with four-parameter curve fit. Relative efficacy was calculated in relation to the most active compound (musk tibetene $=$ $100 \%$ ). Compounds with maximal efficacy $<10 \%$ were considered inactive. 